\title{
Preparation and Characterization of Promoted Fe-V/SiO Nanocatalysts for Oxidation of Alcohols
}

\author{
Hamid Reza Rafiee, ${ }^{1}$ Mostafa Feyzi, ${ }^{1,2}$ Fatanh Jafari, ${ }^{1}$ and Banafsheh Safari ${ }^{1}$ \\ ${ }^{1}$ Faculty of Chemistry, Razi University, P.O. Box +98-67149, Kermanshah, Iran \\ ${ }^{2}$ Nanoscience \& Nanotechnology Research Center (NNRC), Razi University, P.O. Box +98-67149, Kermanshah, Iran \\ Correspondence should be addressed to Mostafa Feyzi; dalahoo2011@yahoo.com
}

Received 27 May 2013; Accepted 20 August 2013

Academic Editor: Giuseppe Gattuso

Copyright (c) 2013 Hamid Reza Rafiee et al. This is an open access article distributed under the Creative Commons Attribution License, which permits unrestricted use, distribution, and reproduction in any medium, provided the original work is properly cited.

\begin{abstract}
A series of $\mathrm{SiO}_{2}$ supported iron-vanadium catalysts were prepared using sol-gel and wetness impregnation methods. This research investigates the effects of $\mathrm{V}$ and $\mathrm{Cu}$ on the structure and morphology of $\mathrm{Fe} / \mathrm{SiO}_{2}$ catalysts. The $\mathrm{SiO}_{2}$ supported catalyst with the highest specific surface area and pore volume was obtained when it is containing $40 \mathrm{wt} . \% \mathrm{Fe}, 15 \mathrm{wt} . \% \mathrm{~V}$, and $2 \mathrm{wt} . \% \mathrm{Cu}$. Characterization of prepared catalysts was carried out by powder X-ray diffraction (XRD), scanning electron microcopy (SEM), vibrating sample magnetometry (VSM), Fourier transform infrared (FT-IR) spectrometry, temperature program reduction (TPR), $\mathrm{N}_{2}$ physisorption, and thermal analysis methods such as thermal gravimetric analysis (TGA) and differential scanning calorimetry (DSC). The $\mathrm{Fe}-\mathrm{V} / \mathrm{SiO}_{2}$ catalyst promoted with $2 \mathrm{wt} . \%$ of $\mathrm{Cu}$ exhibited typical ferromagnetic behavior at room temperature with a saturation magnetization value of $11.44 \mathrm{emu} / \mathrm{g}$. This character of catalyst indicated great potential for application in magnetic separation technologies. The prepared catalyst was found to act as an efficient recoverable nanocatalyst for oxidation reaction of alcohols to aldehydes and ketones in aqueous media under mild condition. Moreover, the catalyst was reused five times without significant degradation in catalytic activity and performance.
\end{abstract}

\section{Introduction}

The synthesis of nanostructured magnetic materials has become a particularly important area of research and is attracting a growing interest due to their chemical and physical properties, which differ significantly from bulk material. This leads to a broad range of applications such as hyperthermia [1], information storage media [2], magnetic resonance imaging (MRI) [3, 4], drug delivery and bioadsorption [5], and catalytic applications [6-8]. Magnetic nanoparticles have been synthesized with a number of different compositions and phases, including pure metals $\mathrm{Fe}, \mathrm{Co}$, and $\mathrm{Ni}$ [9-11]; metal oxides, $\mathrm{Fe}_{3} \mathrm{O}_{4}$ and $\gamma$ - $\mathrm{Fe}_{2} \mathrm{O}_{3}[12,13]$; ferrites, such as $\mathrm{Co}_{1-x}$ $\mathrm{Zn}_{x} \mathrm{Fe}_{2} \mathrm{O}_{4}$ [14]; metal alloys, as $\mathrm{Fe} / \mathrm{Cu}$ [15]; and supported solid catalyst such as iron oxide nanoparticles in a silica matrix [16]. The use of magnetic nanoparticles as the catalysts has been attracting great attention as a useful strategy for improving the catalytic efficiency of heterogeneous catalysts in a wide range of synthetic transformations. Nanometer magnetic solid base catalyst can be separated easily from the reagents by applying an external magnetic field, which can effectively prevent catalyst loss and improve its recovery rate during separation process and can increase the durability of the catalyst. Furthermore, magnetic nanoparticles-supported solid catalyst shows high dispersion to contact reactants more sufficiently based on the high surface area of the supported magnetic nanoparticles [17]. In particular magnetic nanosized transition metal oxides are considered as promising catalysts of various reactions, particularly oxidation of organic substrates [18]. Varying the fabrication conditions of such oxides is the main method used to control their phase composition, size, or surface and thus their properties, which strongly depends on the above mentioned structural features. In fact the catalytic and other properties depend on the morphology, particle size, and surface area. Moreover, the preparation method plays a key role in determining the particle size and shape, size distribution, surface chemistry, and therefore the applications of the material. Preparation of the magnetic nanoparticles requires several tasks, such as control of the size and size distribution of the particles, 
control of the morphology and crystallinity, and prevention of the agglomeration. Different preparation methods have been developed in order to obtain desirable samples and physical properties: thermal decomposition, ultrasonic spray pyrolysis (USP), chemical vapor deposition, and sonochemical technique [19-22]. Yin et al. reported synthesis of cubic $\alpha-\mathrm{Fe}_{2} \mathrm{O}_{3}$ (hematite) microparticles via a simple one-step hydrothermal reaction [23]. Iron and iron oxide nanoparticles in silica layers were deposited by sol-gel techniques prepared by Šimkien et al. [24]. It was shown that multifunctional nanoparticles of different iron oxides possessing various physical properties can be fabricated by means of postgrowth annealing of $\left(\mathrm{SiO}_{2}: \mathrm{Fe}\right) / \mathrm{SiO}_{2} / \mathrm{Si}$ samples in various atmospheres. The hematite, maghemite, and iron nanoparticles were found to be dominant upon annealing the samples in air, argon, and hydrogen atmosphere, respectively. The synthesis of monodispersed $\gamma$ - $\mathrm{Fe}_{2} \mathrm{O}_{3}$ nanoparticles by mechanochemical processing indicated that the nanoparticles had a volume-weighted mean diameter of $6 \mathrm{~nm}$ and a narrow size distribution with the standard deviation of $3 \mathrm{~nm}$ [25]. Orolínová et al. [26] reported that synthesis of magnetic clay composite prepared by the method of precipitation of iron oxide onto the clay surface was subjected to a heat treatment. The sol-gel method has been shown to be very useful for preparation of iron oxide nanoparticles dispersed in an amorphous silica matrix. Silica is convenient because of its nontoxic nature, high biocompatibility, prevention of agglomeration, temperature resistance, chemical inertness, and adjustable pore diameter $[27,28]$. The aim of this study is the synthesis of magnetic $\mathrm{Fe}-\mathrm{V} / \mathrm{SiO}_{2}$ nanocatalysts promoted by copper via sol-gel and impregnation method for oxidation of organic compounds. Characterization of catalysts was carried out using XRD, SEM, TPR, TGA, DSC, and $\mathrm{N}_{2}$ adsorption-desorption measurements. We also report the magnetic properties measured by a vibrating sample magnetometer (VSM).

\section{Experimental}

2.1. Synthesis of Fe/SiO ${ }_{2}$ Nanocatalyst. All materials with analytical purity were purchased from Merck and used without further purification. The supported iron catalysts with different amount of $\mathrm{Fe}(40,50,60,70$ and $80 \mathrm{wt} . \%)$ were prepared using sol-gel method. Iron nitrate $\mathrm{Fe}\left(\mathrm{NO}_{3}\right)_{3} \cdot 9 \mathrm{H}_{2} \mathrm{O}$, tetraethoxysilane, TEOS, and oxalic acid $\mathrm{H}_{2} \mathrm{C}_{2} \mathrm{O}_{4} \cdot 2 \mathrm{H}_{2} \mathrm{O}$, appropriate amounts for TEOS hydrolysis are separately dissolved in ethanol. The three solutions were heated up to $50^{\circ} \mathrm{C}$ and stirred for $20 \mathrm{~min}$. The TEOS was added to the iron nitrate and subsequently oxalic acid added to the previous mixture under strong stirring at $60^{\circ} \mathrm{C}$ for $2 \mathrm{~h}$. The precipitate composed of iron oxalate and TEOS was progressively hydrolyzed by the hydration water of iron nitrate and mainly oxalic acid, according to the following scheme:

$$
\mathrm{Si}\left(\mathrm{OC}_{2} \mathrm{H}_{5}\right)_{4}+4 \mathrm{H}_{2} \mathrm{O} \longrightarrow \mathrm{Si}(\mathrm{OH})_{4}+4 \mathrm{C}_{2} \mathrm{H}_{5} \mathrm{OH}
$$

In the acidic condition $(\mathrm{pH} \approx 1) \mathrm{Si}(\mathrm{OH})_{4}$ condensed with other materials to homogeneous gel. The monolithic gel was dried at $110^{\circ} \mathrm{C}$ in vacuum for $16 \mathrm{~h}$. At last, the dried powder was calcined $\left(450^{\circ} \mathrm{C}\right.$ for $\left.6 \mathrm{~h}\right)$ to produce solid magnetic composite catalyst.
2.2. Synthesis of Fe-V/SiO $\mathrm{Satalyst}_{2}$. The $\mathrm{Fe}_{2} \mathrm{O}_{3} / \mathrm{SiO}_{2}$ was synthesized in Section 2.1 and then was impregnated with an aqueous solution containing $\mathrm{NH}_{4} \mathrm{VO}_{3}(1 \mathrm{M})$ by adding different wt. $\%$ of $\mathrm{V}(x=5-20)$ and results show that $x=15 \mathrm{wt} . \%$ is an optimal wt. $\%$. The catalyst containing 40 wt. $\%$ Fe-15 wt.\% $\mathrm{V}$ was impregnated with 1-5 wt.\% of $\mathrm{Cu}$. The optimal catalyst containing $40 \mathrm{wt}$. $\% \mathrm{Fe}-15 \mathrm{wt} . \% \mathrm{~V} / \mathrm{SiO}_{2}$ was promoted with 15 wt.\% of $\mathrm{Cu}$. Then the optimal sample containing $40 \mathrm{wt} . \%$ $\mathrm{Fe}-15 \mathrm{wt} . \% \mathrm{~V} / \mathrm{SiO}_{2}$ was promoted with 2 wt. $\%$ of $\mathrm{Cu}$ dried at $110^{\circ} \mathrm{C}$ for $12 \mathrm{~h}$ and calcined at different calcination conditions (Figure 1).

\subsection{Catalyst Characterization}

2.3.1. X-Ray Diffraction (XRD). The XRD patterns of all the precursor and calcined samples were recorded on a Philips X' Pert $(40 \mathrm{kV}, 30 \mathrm{~mA}) \mathrm{X}$-ray diffractometer, using a $\mathrm{Cu} \mathrm{K} \alpha$ radiation source $(\lambda=1.542 \AA)$ and a nickel filter in the $2 \theta$ range of $4^{\circ}-70^{\circ}$.

2.3.2. $\mathrm{N}_{2}$-Adsorption-Desorption Measurements. The specific surface area (using BET and BJH methods), the total pore volume, and the mean pore diameter were measured using an $\mathrm{N}_{2}$ adsorption-desorption isotherm at liquid nitrogen temperature $\left(-196^{\circ} \mathrm{C}\right)$, using a NOVA 2200 instrument (Quantachrome, USA). Prior to the adsorption-desorption measurements, all the samples were degassed at $110^{\circ} \mathrm{C}$ in an $\mathrm{N}_{2}$ flow for $3 \mathrm{~h}$ to remove the moisture and other adsorbates.

\subsubsection{Thermal Gravimetric Analysis (TGA) and Differential} Scanning Calorimetry (DSC). The TGA and DSC were carried out using simultaneous thermal analyzer (Perkin Elmer) under a flow of dry air with a flow rate of $50 \mathrm{~mL} \mathrm{~min}^{-1}$. The temperature was raised from 20 to $600^{\circ} \mathrm{C}$ using a linear programmer at a heating rate of $3^{\circ} \mathrm{C} \mathrm{min}^{-1}$.

2.3.4. Scanning Electron Microscopy (SEM). The morphologies of prepared nanocatalysts and their precursors were observed by means of an S-360 Oxford Eng scanning electron microscope (USA).

\subsubsection{Temperature-Programmed Reduction (TPR). TPR pro-} files of the $\mathrm{Fe}_{2} \mathrm{O}_{3} / \mathrm{SiO}_{2}$ nanocatalysts were recorded using a micromeritic TPD-TPR 290 system. The TPR for each sample (50 mg) was performed using a mixture gas of $5 \% \mathrm{H}_{2} / 95 \%$ $\operatorname{Ar}(\mathrm{v} / \mathrm{v})$ as the reductant. The sample was heated from 25 to $900^{\circ} \mathrm{C}$ at a heating rate of $5^{\circ} \mathrm{C} \mathrm{min}$. The flow rate of the mixture gas was $50 \mathrm{~mL} \mathrm{~min}^{-1}$.

2.3.6. Fourier Transform Infrared (FTIR) Spectrometry. The FT-IR spectra were recorded with a VERTEX 70 (Bruker, Germany) FT-IR spectrophotometer, equipped with a deuterium triglycine sulfate (DTGS) detector. Samples of 1-2 mg were mixed with $100 \mathrm{mg} \mathrm{KBr}$ and pressed into translucent disks at room temperature. 


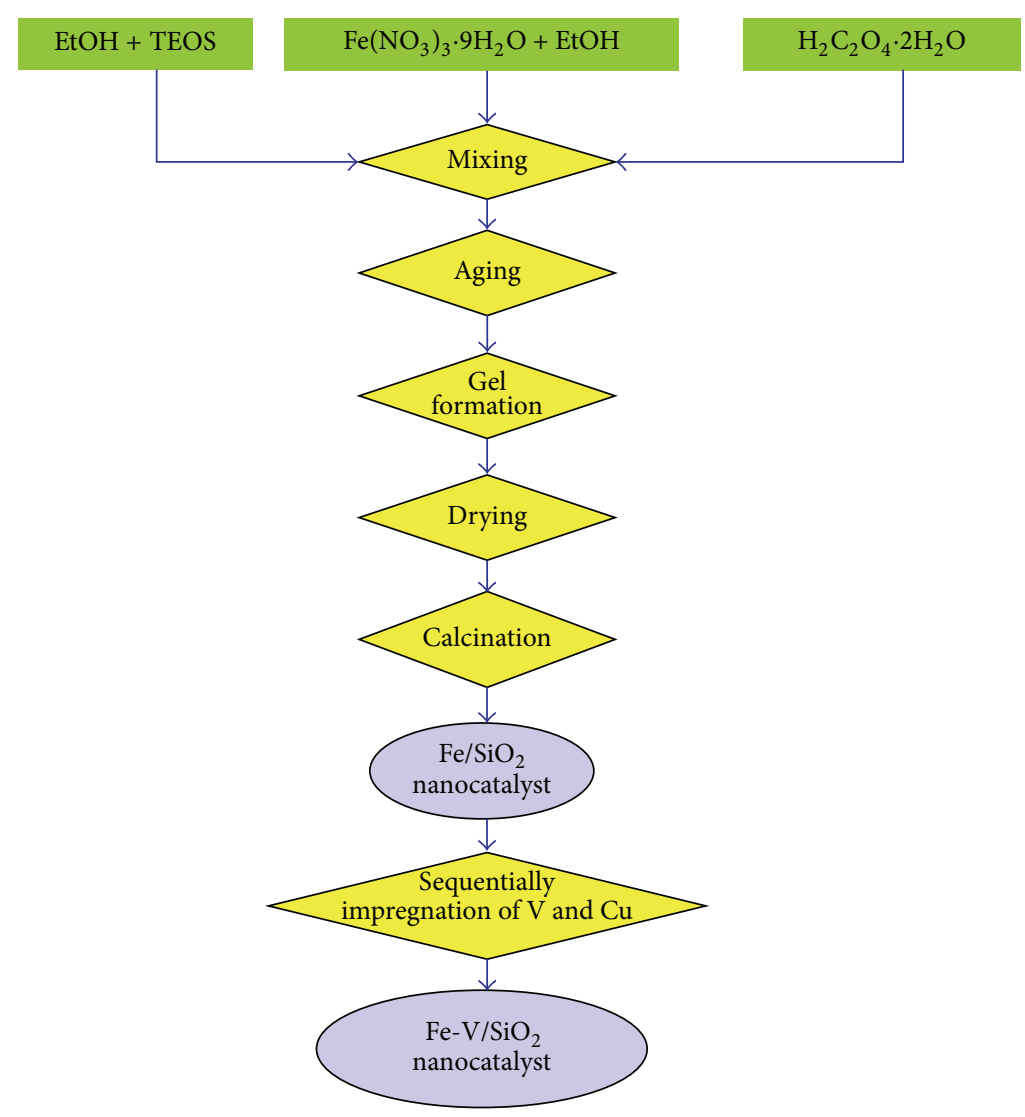

FIGURE 1: Diagram of the chemical process for the preparation of $\mathrm{Fe}-\mathrm{V} / \mathrm{SiO}_{2}$ nanocatalyst.

All spectra were taken in the range $4000-400 \mathrm{~cm}^{-1}$ at a resolution of $4 \mathrm{~cm}^{-1}$. The spectra of all samples were presented by subtracting the background spectrum.

2.3.7. Vibrating Sample Magnetometer (VSM). The magnetic measurements of final catalyst were carried out in a vibrating sample magnetometer (VSM, BHV-55, Riken, Japan) at room temperature.

\section{Results and Discussion}

3.1. Effect of Loading of Fe. One of the most important factors which have influences on the magnetic properties, specific surface area, and morphology of the catalyst is the loading of $\mathrm{Fe}$. To understand this, a series of $\mathrm{Fe} / \mathrm{SiO}_{2}$ catalysts having different weight $\%$ of $\mathrm{Fe}(40,50,60,70$ and 80$)$ were prepared at calcination conditions: $T=450^{\circ} \mathrm{C}, 6 \mathrm{~h}$, and heating rate of $3^{\circ} \mathrm{C} \mathrm{min}$. The preparation conditions are effective on porosity and surface area of $\mathrm{Fe} / \mathrm{SiO}_{2}$ catalyst. To indicate this, the $\mathrm{N}_{2}$ absorption-desorption isotherms of catalyst samples were taken for evaluating the specific surface area, pore volume, and pore size distribution. Figure 2 represents these characters for $\mathrm{Fe} / \mathrm{SiO}_{2}$ catalysts that were prepared with different wt.\% of Fe.

The obtained results in Figure 2 show that the Fe loading can be affected on the specific surface area pore volume and pore size distribution of all catalysts. Furthermore, it is apparent that amount of Fe significantly influences the increasing of the surface area, pore volume, and pore size distribution of catalysts. It is probably due to increasing amount of $\mathrm{SiO}_{2}$ which facilitates the high dispersion of the catalyst crystallites. The specific surface area, pore volume, and pore diameter results for the calcined catalysts containing different wt.\% of Fe have shown that the specific surface area value and pore volume for the calcined catalyst containing $40 \mathrm{wt} . \%$ of Fe are relatively higher than those of the other calcined samples. The $\mathrm{N}_{2}$ absorption-desorption data have shown that the catalyst containing $60 \mathrm{wt} . \%$ of Fe has higher pore diameter than the other calcined catalysts. So the optimum value for iron loading is $40 \mathrm{wt}$. percent. Characterization studies were carried out using XRD technique for the $\mathrm{Fe} / \mathrm{SiO}_{2}$ catalyst (Figure 3). The actual identified phases for this catalyst were $\mathrm{Fe}_{2} \mathrm{SiO}_{4}$ (cubic) and $\mathrm{Fe}_{2} \mathrm{O}_{3}$ (rhombohedral). $\mathrm{H}_{2}$-TPR profiles of $\mathrm{Fe}-\mathrm{V} / \mathrm{SiO}_{2}$ nanocatalyst are depicted in Figure 6. The reduction process of the $\mathrm{Fe} / \mathrm{SiO}_{2}$ nanocatalyst occurs in two distinct stages. The first stage (around $415^{\circ} \mathrm{C}$ ) is ascribed to the transformations of $\mathrm{Fe}_{2} \mathrm{O}_{3} \rightarrow \mathrm{Fe}_{3} \mathrm{O}_{4}$ whereas the second stage (around $530^{\circ} \mathrm{C}$ ) represents the transformation of $\mathrm{Fe}_{3} \mathrm{O}_{4} \rightarrow$ Fe [29]. $\mathrm{H}_{2}$ consumed during different reduction stages was determined by integrating the area of TPR curves. The results have shown that the $\mathrm{H}_{2}$ adsorption for this catalyst is $9.4 \times$ $10^{-2} \mathrm{mmol} \mathrm{H}_{2}$ per mmol of catalyst.

Furthermore, the crystallite sizes of the calcined sample containing $40 \mathrm{wt} . \%$ of Fe were calculated from the major 


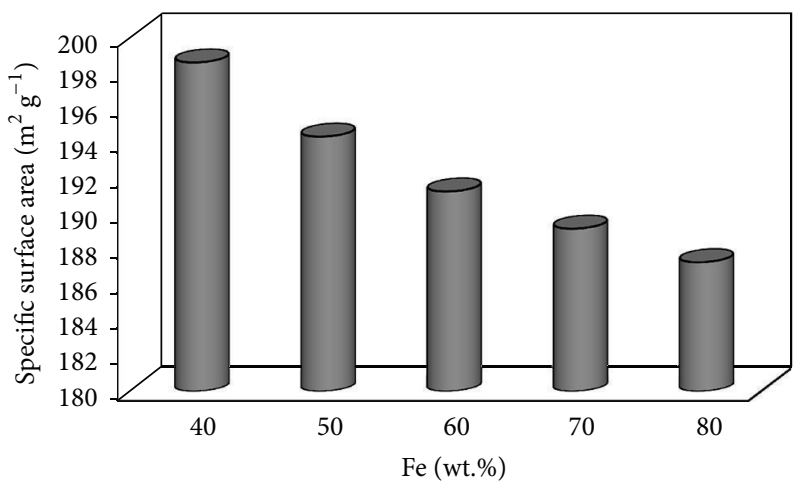

(a)

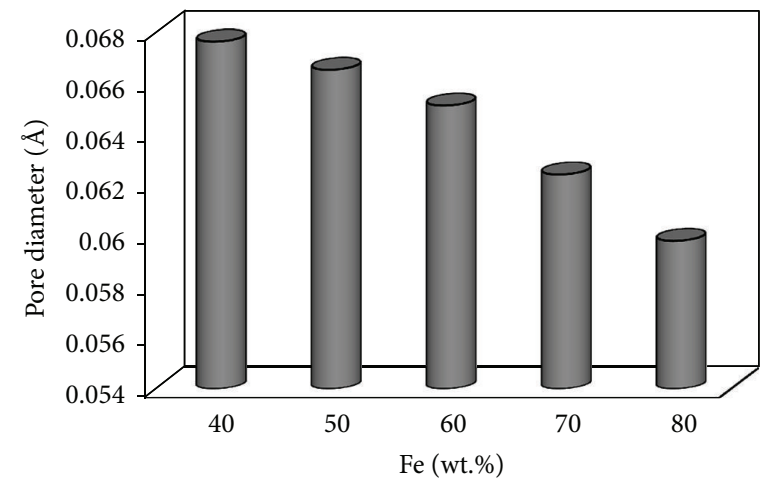

(b)

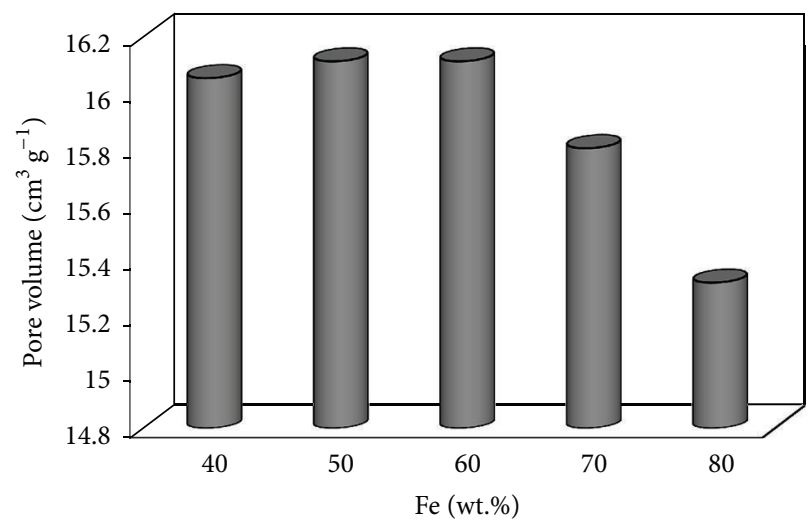

(c)

Figure 2: $\mathrm{N}_{2}$ adsorption-desorption measurements of $\mathrm{Fe} / \mathrm{SiO}_{2}$ catalysts with different wt.\% of Fe.

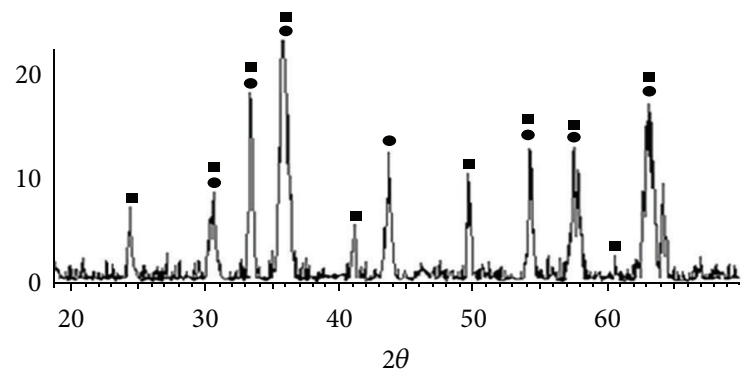

- $\mathrm{Fe}_{2} \mathrm{SiO}_{4}$

- $\mathrm{Fe}_{2} \mathrm{O}_{3}$

FIGURE 3: XRD patterns of the $\mathrm{Fe} / \mathrm{SiO}_{2}$ nanocatalyst.

diffraction peaks in XRD pattern using the Debye-Scherrer equation [30]. The particle size of the calcined catalyst containing $40 \mathrm{wt} . \%$ of Fe was calculated from the most intense line $\left(2 \theta=36^{\circ}\right)$ and it is about $55 \mathrm{~nm}$. It is clear that the catalyst particle size was in nanodimension $(55 \mathrm{~nm})$. The sample containing $40 \mathrm{wt} \%$ of Fe was characterized with SEM (Figure 4(b)). It is obvious in this figure that the crystal sizes were from 42 to $60 \mathrm{~nm}$. This result confirmed the obtained results studied using the Scherrer equation.

The XRD technique may not be sufficiently sensitive to reveal the fine details of these changes. To get this, a detailed SEM study of both precursor and calcined $\mathrm{Fe} / \mathrm{SiO}_{2}$ nanocatalyst was done and the results are given in Figure 4. SEM observations have shown differences in morphology of precursor and calcined catalysts. The image obtained from catalyst precursor depicts several larger agglomerations of particles (Figure 4(a)) and shows that this material has a less dense and homogeneous morphology. After the calcination at $450^{\circ} \mathrm{C}$ for 6 hours and heating rate of $3^{\circ} \mathrm{C} \mathrm{min}^{-1}$, the morphological features were different with the precursor samples and show that the agglomerate size is greatly reduced compared to the precursor (Figure 4(b)). It may be assigned to the covering of calcined catalyst surface by small crystallite of iron oxides, in agreement with XRD results. The TGA curve for $\mathrm{Fe} / \mathrm{SiO}_{2}$ catalyst precursor is shown in Figure 5. The weight losses found from TGA measurements agree fairly well with those expected for the decomposition of hydroxyl or oxalate phases to oxides. For this catalyst precursor, the thermogravimetric curve seems to indicate three-stage decomposition. The firststage is considered to be due to the removal of adsorbed water and ethanol $\left(25-195^{\circ} \mathrm{C}\right)$ while the second stage comes from the decomposition of hydroxyl phases $\left(230-370^{\circ} \mathrm{C}\right)$, respectively. The third stage around $390-420^{\circ} \mathrm{C}$ is the result of the full decomposition of hydroxyl and oxalate phases to oxides. The TGA curve is involved with a total overall weight loss of ca. 40 wt.\%. DSC measurement was performed in order to provide further evidence for the presence of the various species and evaluate their thermal behavior. As it is shown in Figure 5, the exothermic peak at lower temperature 

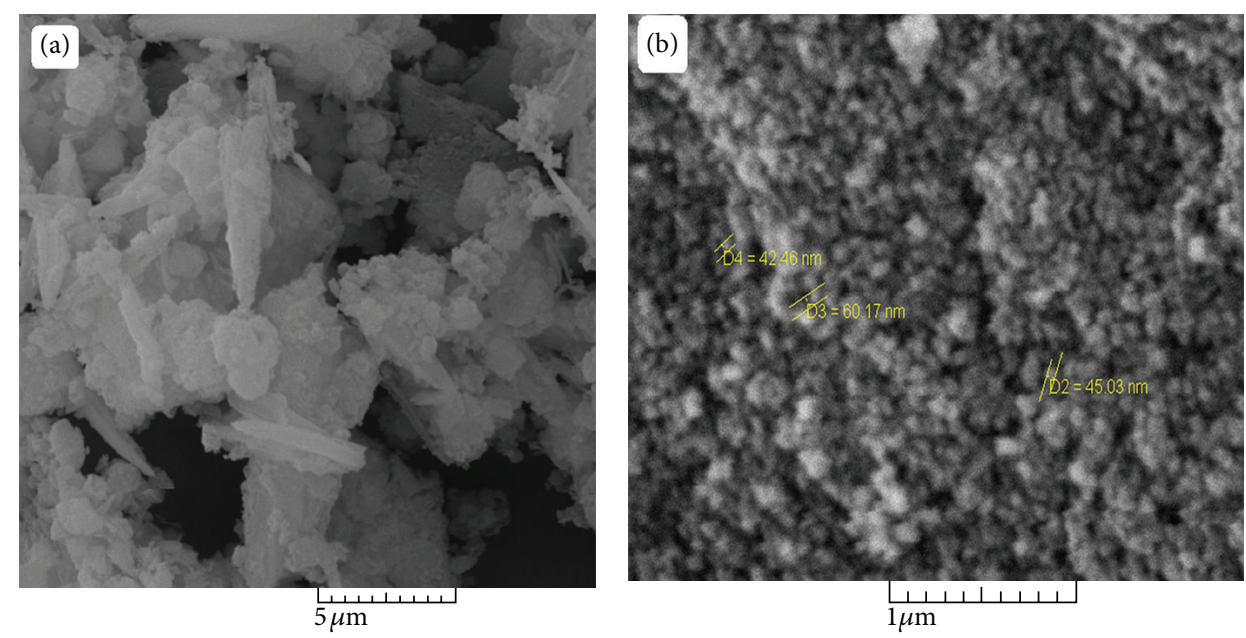

FIGURE 4: The SEM images of $\mathrm{Fe} / \mathrm{SiO}_{2}$ nanocatalyst, (a) precursor and (b) calcined catalyst.

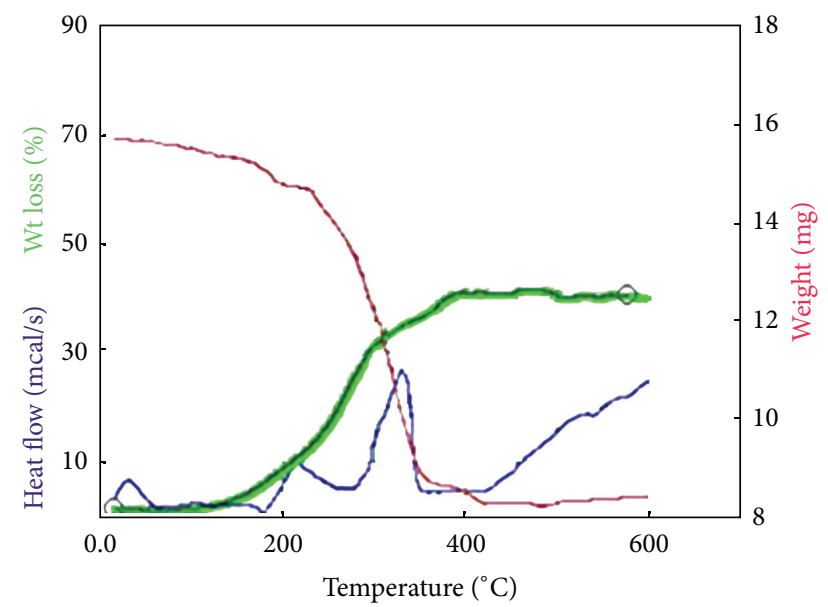

Figure 5: TGA and DSC curves for $\mathrm{Fe} / \mathrm{SiO}_{2}$ precursor.

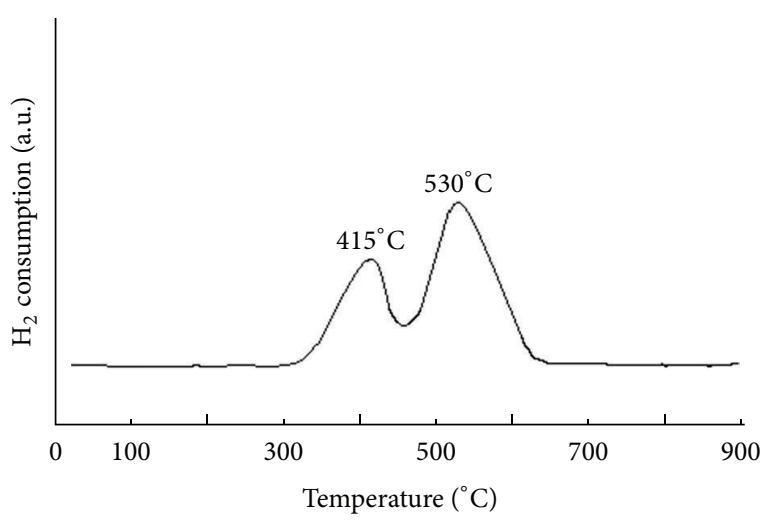

FIGURE 6: TPR profile of $\mathrm{Fe} / \mathrm{SiO}_{2}$ nanocatalyst.

represents the removal of the physically adsorbed water and ethanol from the material. The endothermic peaks around $230-370^{\circ} \mathrm{C}$ and $280-530^{\circ} \mathrm{C}$ are due to the decomposition of hydroxyl and phases, respectively.
3.2. Effect of Heating Rate in Calcinations on the Surface Properties. In order to study the effect of calcination heating rate on the catalyst property, a series of catalyst precursors containing $40 \% \mathrm{Fe} / \mathrm{SiO}_{2}$ were calcined (at $450^{\circ} \mathrm{C}$ for $6 \mathrm{~h}$ ) at various heating rates in air atmosphere. The specific surface area results (BET, $\mathrm{BJH}$, and $\mathrm{DH}$ methods), pore volumes, and pore diameters of the calcined catalysts are given in Table 1. According to the obtained results, the specific surface areas are dependent on the heating rate. When heating rate increases from $2^{\circ} \mathrm{C} / \mathrm{min}$ to $4^{\circ} \mathrm{C} / \mathrm{min}$, the average pore diameter increases a bit, and the surface area decreased from 188.5 to $182.6 \mathrm{~m}^{2} \mathrm{~g}^{-1}$. This may be due to the fact that a great deal of heat cannot be emitted within a short period of time, which induces the agglomeration of nanoparticles [31]. The BET specific surface area results for the calcined catalysts at different heating rates have shown that the specific surface area values obtained for the calcined catalyst in calcination rate $2^{\circ} \mathrm{C} / \mathrm{min}\left(188.5,192.2\right.$, and $193.5 \mathrm{~m}^{2} \mathrm{~g}^{-1}$ measured by different methods) are relatively higher than those observed for those calcined catalysts in 3 and $4^{\circ} \mathrm{C} / \mathrm{min}$. Previous researchers had reported that the activity of the catalyst is depending on BET surface area, pore diameter, and pore volume $[32,33]$. Jacobson et al. [34] reported that pore structure is a primary requirement for an ideal solid catalyst for biodiesel production since a typical triglyceride molecule has a pore diameter of approximately $58 \AA$. The larger average pore diameter and larger interconnected pores would minimize diffusion limitations of reactant molecules. Consequently, the reactants easily diffused into the interior of the catalyst, became in contact with more acid-basic active sites, and lead to better catalytic activity. Besides, all the catalysts could be defined as mesoporous catalysts since the pore diameter of each catalyst was in intermediate range between $2 \mathrm{~nm}$ (micropore) and $50 \mathrm{~nm}$ (macropore). The mesoporous catalyst has been widely used in transesterification reaction in previous studies [35-37]. In addition, the specific pore volume which represents the total internal volume per unit mass of catalyst would facilitate the reaction by amplifying the reaction surface. 
TABLE 1: $\mathrm{N}_{2}$ adsorption-desorption measurements of $\mathrm{Fe} / \mathrm{SiO}_{2}$ nanocatalysts at different calcination heating rates.

\begin{tabular}{|c|c|c|c|c|c|c|c|}
\hline \multirow{2}{*}{$\begin{array}{l}\text { Heating } \\
\text { rate }\left({ }^{\circ} \mathrm{C} \min ^{-1}\right)\end{array}$} & \multicolumn{3}{|c|}{ Specific surface area $\left(\mathrm{m}^{2} \mathrm{~g}^{-1}\right)$} & \multicolumn{2}{|c|}{ Pore diameter $(\AA)$} & \multicolumn{2}{|c|}{ Pore volume $\left(\mathrm{cm}^{3} \mathrm{~g}^{-1}\right)$} \\
\hline & BET & $\mathrm{BJH}$ & $\mathrm{DH}$ & $\mathrm{BJH}$ & $\mathrm{DH}$ & $\mathrm{BJH}$ & $\mathrm{DH}$ \\
\hline 2 & 188.5 & 192.2 & 193.5 & 74.4 & 74.7 & 16.5 & 16.49 \\
\hline 3 & 185.7 & 187 & 189.2 & 72.0 & 72.8 & 16.94 & 16.98 \\
\hline 4 & 182.6 & 183.1 & 184.2 & 71.0 & 72.0 & 16.81 & 16.89 \\
\hline
\end{tabular}

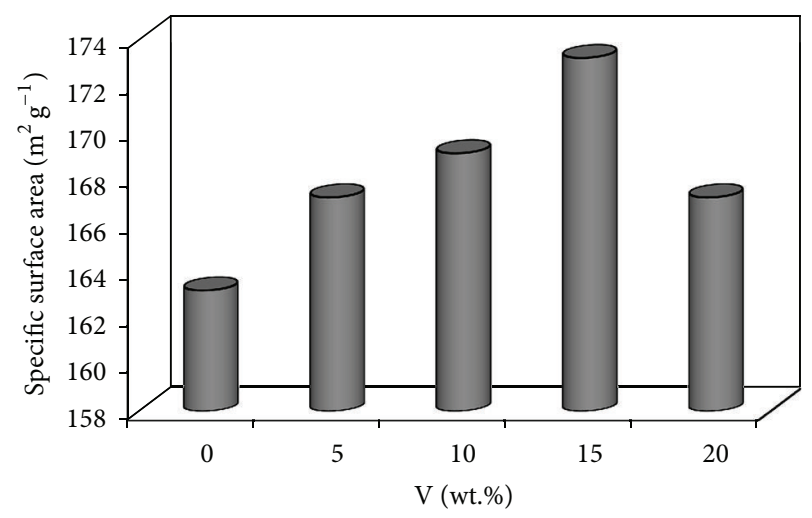

(a)

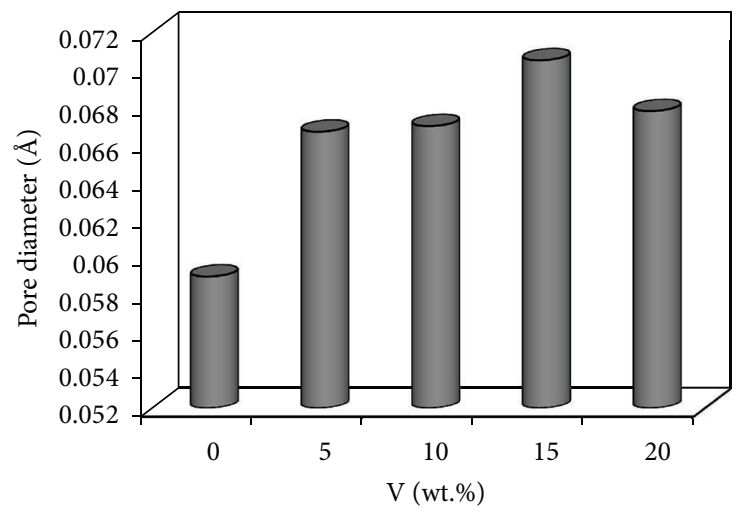

(b)

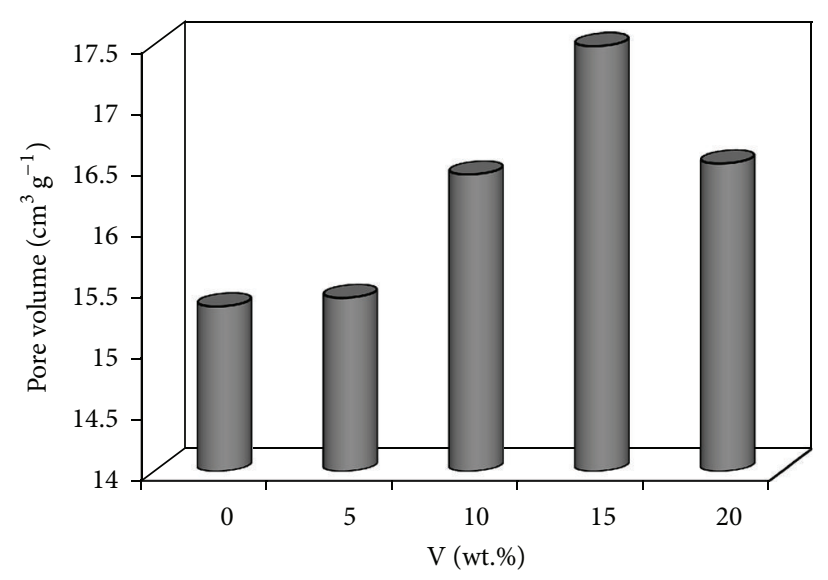

(c)

Figure 7: $\mathrm{N}_{2}$ adsorption-desorption measurements of $\mathrm{Fe}-\mathrm{V} / \mathrm{SiO}_{2}$ nanocatalysts at different $\mathrm{V}$ loading.

3.3. Effect of Loading of Vanadium on the Surface Properties. Figure 7 represents the results of surface factors for $40 \mathrm{wt} . \%$ $\mathrm{Fe}-x \mathrm{~V} / \mathrm{SiO}_{2}$ nanocatalysts which impregnated with different weight percents of $\mathrm{V}(x=5,10,15$, and $20 \mathrm{wt}$. $\%$ of $\mathrm{V}$ based on the $\mathrm{SiO}_{2}$ weight). The obtained results in Figure 7 show that the $\mathrm{V}$ loading can be by affected the surface properties of catalyst. As can be seen at first, amount of $\mathrm{V}$ significantly increases the surface area, pore volume and pore size distribution of Fe$\mathrm{V} / \mathrm{SiO}_{2}$ nanocatalysts and then they decreased. It can be seen that the calcined catalyst containing $15 \mathrm{wt} . \%$ of $\mathrm{V}$ has higher specific surface area than the other prepared catalysts. On the other hand, as it can be seen from Figure 7, with the increase in wt.\% of $\mathrm{V}$, the specific surface area increased at first and then decreased when 15 wt. $\%$ of $V$ loaded, which is due to the blockage of the micropores of $\mathrm{SiO}_{2}$. This occurs because the impregnation of the support with metal clogs the pores of the $\mathrm{SiO}_{2}[39,40]$.
3.4. Effect of Loading of Cu. The effect of wt.\% of $\mathrm{Cu}$ was studied (1, 2, 3, 4, and 5 wt. \% based on the total Fe and V weight) on the catalyst properties of the $\mathrm{Fe}-\mathrm{V} / \mathrm{SiO}_{2}$ catalyst. The effect of adding copper to the $40 \mathrm{wt} . \% \mathrm{Fe}-15 \mathrm{wt} . \% \mathrm{~V} / \mathrm{SiO}_{2}$ catalysts is mainly an increase in the rate of reduction of iron, leading to a larger number of active sites [41]. The additives are effective on porosity and surface area of catalyst. To evaluate this, the $\mathrm{N}_{2}$ absorption-desorption isotherms of catalyst samples were analyzed for specific surface area measurements, pore volume, and pore size distribution. The pore structure and the specific surface area of catalysts were obtained using BJH, $\mathrm{DH}$, and BET methods and the results are shown in Table 2. It can be clearly seen that the addition of different amounts of copper increases the BET surface area of the catalysts, but further increase in $\mathrm{Cu}$ results in a decrease in surface area. The results may be ascribed to the improved dispersion of iron and vanadium oxides at low $\mathrm{Cu}$ loading [42]. However, 
TABLE 2: Textural properties of the catalysts with different copper contents.

\begin{tabular}{lccccccc}
\hline \multirow{2}{*}{ Wt.\% Cu } & \multicolumn{2}{c}{ Specific surface area $\left(\mathrm{m}^{2} \mathrm{~g}^{-1}\right)$} & \multicolumn{2}{c}{ Pore diameter $(\AA)$} & \multicolumn{3}{c}{ Pore volume $\left(\mathrm{cm}^{3} \mathrm{~g}^{-1}\right)$} \\
& BET & BJH & DH & BJH & DH & BJH & DH \\
\hline 0 & 173.2 & 174.4 & 177.1 & 70.5 & 71.2 & 17.48 & 17.61 \\
2 & 179.6 & 178.5 & 181.3 & 70.7 & 71.1 & 16.75 & 16.83 \\
3 & 173.4 & 173.1 & 175.9 & 62.4 & 62.7 & 16.03 & 15.98 \\
5 & 170.4 & 171.3 & 170.6 & 60.2 & 60.8 & 15.96 \\
\hline
\end{tabular}

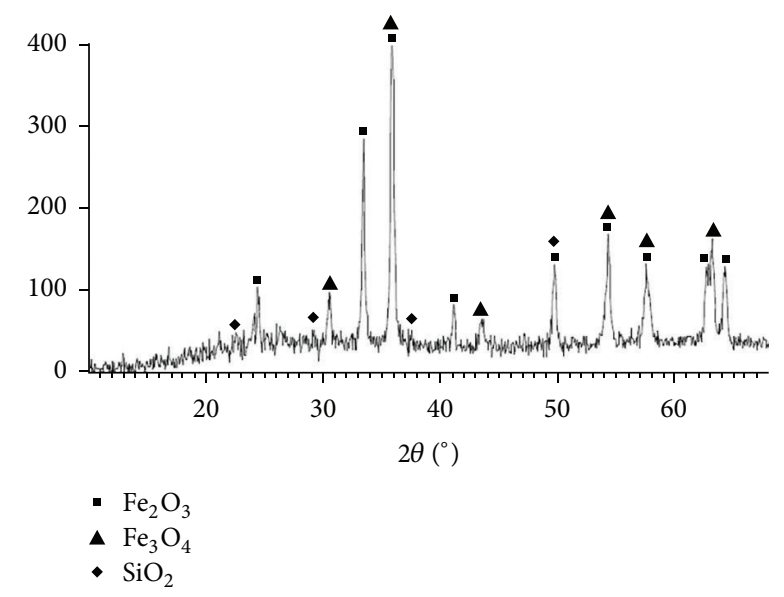

FIGURE 8: XRD patterns of the $\mathrm{Fe}-\mathrm{V} / \mathrm{SiO}_{2}$ promoted with copper nanocatalyst.

the promotional effect on dispersion is possibly offset by another factor, which is the blockage of mesoporous of catalyst by further $\mathrm{Cu}$ loading. This postulated explanation can be evidenced by the pore size distribution of the catalysts.

The increment in surface area might be due to the strong interaction of the $\mathrm{Cu}$ with $\mathrm{SiO}_{2}$ support, which reduced the surface diffusion of $\mathrm{Fe}$, inhibited sintering, and stabilized the crystal surface of $\mathrm{SiO}_{2}$. Characterization studies were carried out using XRD technique for the final calcined $\mathrm{Fe}-\mathrm{V} / \mathrm{SiO}_{2}$ nanocatalysts. Figure 8 shows the XRD pattern of the $40 \mathrm{wt} . \%$ Fe- 15 wt. $\% \mathrm{~V} / \mathrm{SiO}_{2}$ catalyst that was promoted with $2 \mathrm{wt}$. \% of $\mathrm{Cu}$ as optimal catalyst. The actual identified phases for this catalyst were $\mathrm{Fe}_{2} \mathrm{O}_{3}$ (rhombohedral), $\mathrm{Fe}_{3} \mathrm{O}_{4}$ (cubic), and $\mathrm{SiO}_{2}$ (tetragonal). From the XRD data, the crystallite size of the prepared nanocatalyst was calculated to be $46 \mathrm{~nm}$.

The FT-IR spectrum of catalyst is shown in Figure 9. Broad peak at $3447 \mathrm{~cm}^{-1}$ could be correlated to the vibration of structural $\mathrm{OH}$ [43]. The bands at 1083, 800 , and $452 \mathrm{~cm}^{-1}$ are attributed to the asymmetric $\mathrm{Si}-\mathrm{O}-\mathrm{Si}$ stretching vibration, the symmetric $\mathrm{Si}-\mathrm{O}-\mathrm{Si}$ stretching vibration, and the $\mathrm{O}-\mathrm{Si}-\mathrm{O}$ shearing vibration $[44,45]$. The bands around $1000 \mathrm{~cm}^{-1}$ were assigned to the asymmetric $\mathrm{Fe}-\mathrm{O}-\mathrm{Si}$ stretching vibration [44, $46,47]$. These results suggested that the $\mathrm{Fe}-\mathrm{SiO}_{2}$ interaction exists in the catalyst in a form of $\mathrm{Fe}-\mathrm{O}-\mathrm{Si}$ structure. The band at $551 \mathrm{~cm}^{-1}$ can be assigned to the $\mathrm{Fe}-\mathrm{O}$ stretching in $\mathrm{Fe}-\mathrm{O}-\mathrm{Si}$ bonds [43].

The magnetic properties of the nanoparticles were characterized using a vibrating sample magnetometer (VSM). The room temperature magnetization curve of the final catalyst is

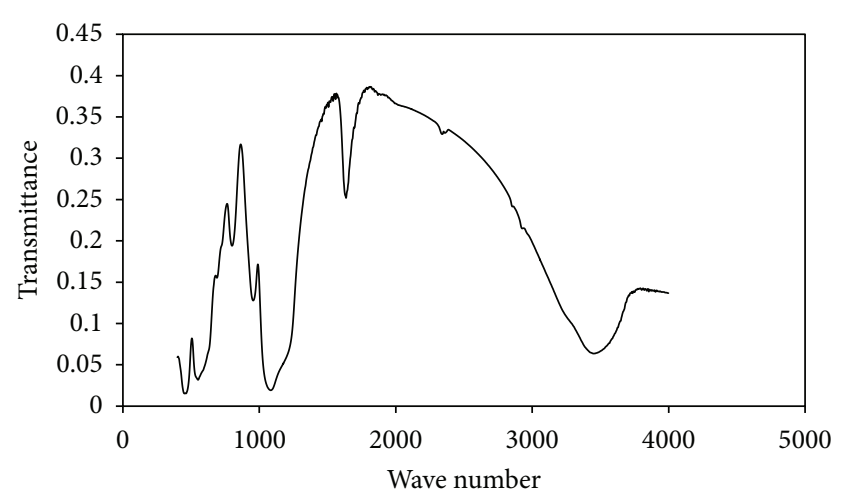

FIGURE 9: FT-IR spectrum of the $\mathrm{Fe}-\mathrm{V} / \mathrm{SiO}_{2}$ promoted with copper nanocatalyst.

shown in Figure 10. The sample exhibited typical ferromagnetic behavior at room temperature. The observed value of saturation magnetization of the sample was $11.44 \mathrm{emu} / \mathrm{g}$.

3.5. Catalytic Performance of Optimal Catalyst. The synthesized optimal nanocatalyst (40 wt.\% Fe- 15 wt.\% $\mathrm{V} / \mathrm{SiO}_{2}$ catalyst that was promoted with $2 \mathrm{wt} . \%$ of $\mathrm{Cu}$ ) was employed for oxidation reaction of alcohols to aldehydes and ketones. We carry out these reactions under atmospheric oxygen (Scheme 1).

The progress of reactions was monitored by TLC. Table 3 gives the oxidation results. Compared to what Velusamy et al. reported [48] our catalyst has a better performance for the mentioned reactions. The observed shorter reaction times compared to their catalyst (e.g., forecasted time is $22-25$ hour and reaction time is 20 hour) can be interpreted by considering the fact that $\mathrm{Fe}-\mathrm{V} / \mathrm{SiO}_{2}$ nanocatalyst has a higher surface area compared to their catalyst. Also after completion of the reactions, recovery of $\mathrm{Fe}-\mathrm{V} / \mathrm{SiO}_{2}$ nanocrystals from the reaction mixture was easily achieved by applying an external permanent magnet on the outside wall of the reaction tube, as shown in Figure 11. Therefore, the products were isolated in good purity after the volatile portions were removed and the product was purified. All isolated products gave satisfactory spectral data $\left({ }^{1} \mathrm{H}\right.$ NMR) compared with those reported in the literature [48]. At the end of the reaction, to determine the applicability of catalyst recovery, we decanted the vessel by the use of an external magnet and remained catalyst was washed with diethyl ether to remove residual product and then dried under vacuum. 
TABLE 3: Catalyzed oxidation reactions.

\begin{tabular}{|c|c|c|c|c|c|}
\hline Entry & Substrate & Product & $\begin{array}{c}\text { Time } \\
(\mathrm{h})\end{array}$ & $\begin{array}{l}\text { M.P }\left({ }^{\circ} \mathrm{C}\right) \\
\text { found }\end{array}$ & $\begin{array}{c}\text { M.P }\left({ }^{\circ} \mathrm{C}\right) \text { reported } \\
{[38]}\end{array}$ \\
\hline 1 & & & 12 & Oil & -26 \\
\hline 2 & & & 18 & Oil & 0 \\
\hline 3 & & & 20 & 104 & 105 \\
\hline 4 & & & 11 & Oil & -7.5 \\
\hline 5 & & & 8 & 19 & 20 \\
\hline 6 & & & 13 & 48 & 48 \\
\hline
\end{tabular}

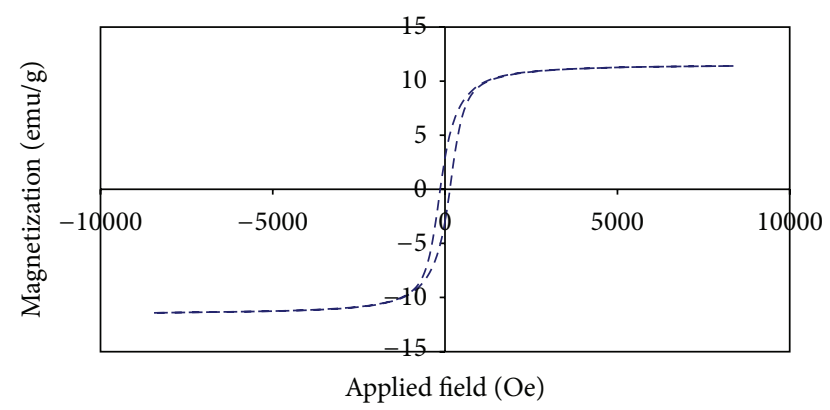

FIgURE 10: Hysteresis loop for $\mathrm{Fe}-\mathrm{V} / \mathrm{SiO}_{2}$ nanocrystals at room temperature.

\section{Conclusions}

The preparation and characterization of $\mathrm{Fe}-\mathrm{V} / \mathrm{SiO} \mathrm{O}_{2}$ nanocrystals were described in this work. Synthesized material acts as a powerful and heterogeneous catalyst for oxidation reactions. Therefore can utilize in mild reaction conditions, shorter reaction times, product purity and therefore cost efficiency are of advantages of this nanocatalyst. Besides that, the new catalyst can be effectively reused. With regard to observed satisfactory catalytic properties, it is expected that it can be a good potentially substitute for some commercial catalysts.

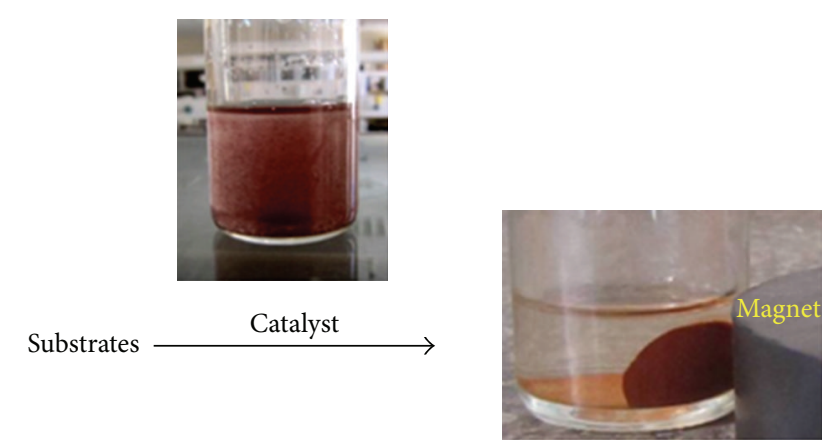

FIGURE 11: Magnetic properties of optimal nanocatalyst can lead to its separation from the reaction medium.

$$
\begin{aligned}
& \overbrace{\mathrm{R}^{\prime}}^{\mathrm{OH}} \frac{\begin{array}{c}
5 \mathrm{~mol} \% \text { nanocatalyst } \\
\mathrm{O}_{2}(1 \mathrm{~atm})
\end{array}}{\text { toluene, } 100^{\circ} \mathrm{C}} \\
& \widehat{\mathrm{R}}_{\mathrm{OH}} \frac{\begin{array}{c}
5 \mathrm{~mol} \% \text { nanocatalyst } \\
\mathrm{O}_{2}(1 \mathrm{~atm})
\end{array}}{0.5 \mathrm{eq}, \mathrm{K}_{2} \mathrm{CO}_{3}} \mathrm{R}^{\text {toluene, } 100^{\circ} \mathrm{C}} \overbrace{\mathrm{H}}^{\mathrm{O}} \mathrm{R}: \mathrm{Ar} \text {, alkyl }
\end{aligned}
$$

SCHeme 1: $\mathrm{Fe}-\mathrm{V} / \mathrm{SiO}_{2}$ catalyzed oxidation reactions. 


\section{References}

[1] J.-P. Fortin, C. Wilhelm, J. Servais, C. Ménager, J.-C. Bacri, and F. Gazeau, "Size-sorted anionic iron oxide nanomagnets as colloidal mediators for magnetic hyperthermia," Journal of the American Chemical Society, vol. 129, no. 9, pp. 2628-2635, 2007.

[2] Z. Jing, Y. Wang, and $\mathrm{S}$. Wu, "Preparation and gas sensing properties of pure and doped $\gamma-\mathrm{Fe}_{2} \mathrm{O}_{3}$ by an anhydrous solvent method," Sensors and Actuators, vol. 113, no. 1, pp. 177-181, 2006.

[3] M. C. Bautista, O. Bomati-Miguel, X. Zhao et al., "Comparative study of ferrofluids based on dextran-coated iron oxide and metal nanoparticles for contrast agents in magnetic resonance imaging," Nanotechnology, vol. 15, no. 4, pp. S154-S159, 2004.

[4] N. Kohler, C. Sun, A. Fichtenholtz, J. Gunn, C. Fang, and M. Zhang, "Methotrexate-immobilized poly(ethylene glycol) magnetic nanoparticles for MR imaging and drug delivery," Small, vol. 2, no. 6, pp. 785-792, 2006.

[5] S. Huang, C. Li, Z. Cheng et al., "Magnetic $\mathrm{Fe}_{3} \mathrm{O}_{4}$ mesoporous silica composites for drug delivery and bioadsorption," Journal of Colloid and Interface Science, vol. 376, no. 1, pp. 312-321, 2012.

[6] B. V. S. Reddy, A. S. Krishna, A. V. Ganesh, and G. G. K. S. N. Kumar, "Nano $\mathrm{Fe}_{3} \mathrm{O}_{4}$ as magnetically recyclable catalyst for the synthesis of $\alpha$-aminophosphonates in solvent-free conditions," Tetrahedron Letters, vol. 52, no. 12, pp. 1359-1362, 2011.

[7] M. Masteri-Farahani and Z. Kashef, "Synthesis and characterization of new magnetically recoverable molybdenum nanocatalyst for epoxidation of olefins," Journal of Magnetism and Magnetic Materials, vol. 324, no. 7, pp. 1431-1434, 2012.

[8] S. Rostamizadeh, M. Azad, N. Shadjou, and M. Hasanzadeh, "(Alpha- $\mathrm{Fe}_{2} \mathrm{O}_{3}$ )-MCM-41- $\mathrm{SO}_{3} \mathrm{H}$ as a novel magnetic nanocatalyst for the synthesis of $\mathrm{N}$-aryl-2-amino-1, 6-naphthyridine derivatives," Catalysis Communications, vol. 25, pp. 83-91, 2012.

[9] S.-J. Park, S. Kim, S. Lee, Z. G. Khim, K. Char, and T. Hyeon, "Synthesis and magnetic studies of uniform iron nanorods and nanospheres," Journal of the American Chemical Society, vol. 122, no. 35, pp. 8581-8582, 2000.

[10] V. F. Puntes, K. M. Krishnan, and A. P. Alivisatos, "Colloidal nanocrystal shape and size control: the case of cobalt," Science, vol. 291, no. 5511, pp. 2115-2117, 2001.

[11] X. Sun, A. Gutierrez, M. J. Yacaman, X. Dong, and S. Jin, "Investigations on magnetic properties and structure for carbon encapsulated nanoparticles of $\mathrm{Fe}, \mathrm{Co}, \mathrm{Ni}$," Materials Science and Engineering A, vol. 286, no. 1, pp. 157-160, 2000.

[12] M. M. Mojtahedi, M. S. Abaee, A. Rajabi, P. Mahmoodi, and S. Bagherpoor, "Recyclable superparamagnetic $\mathrm{Fe}_{3} \mathrm{O}_{4}$ nanoparticles for efficient catalysis of thiolysis of epoxides," Journal of Molecular Catalysis A, vol. 361-362, pp. 68-71, 2012.

[13] M. S. Islam, J. Kurawaki, Y. Kusumoto, M. Abdulla-Al-Mamun, and M. Z. Bin Mukhlish, "Hydrothermal novel synthesis of neck-structured hyperthermia-suitable magnetic $\left(\mathrm{Fe}_{3} \mathrm{O}_{4}\right.$, gamma- $\mathrm{Fe}_{2} \mathrm{O}_{3}$ and alpha- $\mathrm{Fe}_{2} \mathrm{O}_{3}$ ) nanoparticles," Journal of Scientific Research, vol. 4, pp. 99-107, 2012.

[14] I. Sharifi and H. Shokrollahi, "Nanostructural, magnetic and Mössbauer studies of nanosized $\mathrm{Co}_{1-x} \mathrm{Zn}_{x} \mathrm{Fe}_{2} \mathrm{O}_{4}$ synthesized by co-precipitation," Journal of Magnetism and Magnetic Materials, vol. 324, pp. 2397-2403, 2012.

[15] X. Zhang, B. Wang, and X. Xu, "Synthesis and magnetic properties of Cu-coated Fe composite nanoparticles," Applied Surface Science, vol. 256, no. 13, pp. 4109-4113, 2010.

[16] M. Tadić, V. Kusigerski, D. Marković, M. Panjan, I. Milošević, and V. Spasojević, "Highly crystalline superparamagnetic iron oxide nanoparticles (SPION) in a silica matrix," Journal of Alloys and Compounds, vol. 525, pp. 28-33, 2012.

[17] S. Tang, L. Wang, Y. Zhang, S. Li, S. Tian, and B. Wang, "Study on preparation of $\mathrm{Ca} / \mathrm{Al} / \mathrm{Fe}_{3} \mathrm{O}_{4}$ magnetic composite solid catalyst and its application in biodiesel transesterification," Fuel Processing Technology, vol. 95, pp. 84-89, 2012.

[18] S. C. Tsang, V. Caps, I. Paraskevas, D. Chadwick, and D. Thompsett, "Magnetically separable, carbon-supported nanocatalysts for the manufacture of fine chemicals," Angewandte Chemie, vol. 43, no. 42, pp. 5645-5649, 2004.

[19] F. Zhao, B. Zhang, and L. Feng, "Preparation and magnetic properties of magnetite nanoparticles," Materials Letters, vol. 68, pp. 112-114, 2012.

[20] S. Gurmen and B. Ebin, "Production and characterization of the nanostructured hollow iron oxide spheres and nanoparticles by aerosol route," Journal of Alloys and Compounds, vol. 492, no. 1-2, pp. 585-589, 2010.

[21] V. de Castro, G. Benito, S. Hurst, C. J. Serna, M. P. Morales, and S. Veintemillas-Verdaguer, "One step production of magnetic nanoparticle films by laser pyrolysis inside a chemical vapour deposition reactor," Thin Solid Films, vol. 519, no. 22, pp. 76777682, 2011.

[22] M. Nazrul Islam, L. van Phong, J.-R. Jeong, and C. Kim, "A facile route to sonochemical synthesis of magnetic iron oxide $\left(\mathrm{Fe}_{3} \mathrm{O}_{4}\right)$ nanoparticles," Thin Solid Films, vol. 519, no. 23, pp. 8277-8279, 2011.

[23] C.-Y. Yin, M. Minakshi, D. E. Ralph, Z.-T. Jiang, Z. Xie, and H. Guo, "Hydrothermal synthesis of cubic $\alpha-\mathrm{Fe}_{2} \mathrm{O}_{3}$ microparticles using glycine: surface characterization, reaction mechanism and electrochemical activity," Journal of Alloys and Compounds, vol. 509, no. 41, pp. 9821-9825, 2011.

[24] I. Šimkien, M. Treideris, G. Niaura et al., "Multifunctional iron and iron oxide nanoparticles in silica," Materials Chemistry and Physics, vol. 130, no. 3, pp. 1026-1032, 2011.

[25] T. Tsuzuki, F. Schäffel, M. Muroi, and P. G. McCormick, "Magnetic properties of mechanochemically synthesized $\gamma$ $\mathrm{Fe}_{2} \mathrm{O}_{3}$ nanoparticles," Journal of Alloys and Compounds, vol. 509, no. 17, pp. 5420-5425, 2011.

[26] Z. Orolínová, A. Mockovčiaková, V. Zeleňák, and M. Myndyk, "Influence of heat treatment on phase transformation of clayiron oxide composite," Journal of Alloys and Compounds, vol. 511, no. 1, pp. 63-69, 2012.

[27] I. Ursachi, A. Vasile, A. Ianculescu, E. Vasile, and A. Stancu, "Ultrasonic-assisted synthesis and magnetic studies of iron oxide/MCM-41 nanocomposite," Materials Chemistry and Physics, vol. 130, no. 3, pp. 1251-1259, 2011.

[28] S. Gandhi, S. Venkatesh, U. Sharma, N. R. Jagannathan, S. Sethuraman, and U. M. Krishnan, "Superparamagnetic nanosystems based on iron oxide nanoparticles \& mesoporous silica: synthesis \& evaluation of their magnetic, relaxometric and biocompatability properties," Journal of Materials Chemistry, vol. 21, no. 39, pp. 15698-15707, 2011.

[29] H. Wang, Y. Yang, J. Xu, H. Wang, M. Ding, and Y. Li, "Study of bimetallic interactions and promoter effects of FeZn, FeMn and FeCr Fischer-Tropsch synthesis catalysts," Journal of Molecular Catalysis A, vol. 326, no. 1-2, pp. 29-40, 2010.

[30] R. Jenkins and R. L. Sder, X-Ray Powder Diffractometry, Chemical Analysis, John Wiley and Sons, New York, NY, USA, 1996.

[31] Y. Wu, Y. He, T. Wu, T. Chen, W. Weng, and H. Wan, "Influence of some parameters on the synthesis of nanosized $\mathrm{NiO}$ material by modified sol-gel method," Materials Letters, vol. 61, no. 14-15, pp. 3174-3178, 2007. 
[32] W. Xie, H. Peng, and L. Chen, “Transesterification of soybean oil catalyzed by potassium loaded on alumina as a solid-base catalyst," Applied Catalysis A, vol. 300, no. 1, pp. 67-74, 2006.

[33] H. Sun, Y. Ding, J. Duan et al., "Transesterification of sunflower oil to biodiesel on $\mathrm{ZrO}_{2}$ supported $\mathrm{La}_{2} \mathrm{O}_{3}$ catalyst," Bioresource Technology, vol. 101, no. 3, pp. 953-958, 2010.

[34] K. Jacobson, R. Gopinath, L. C. Meher, and A. K. Dalai, "Solid acid catalyzed biodiesel production from waste cooking oil," Applied Catalysis B, vol. 85, no. 1-2, pp. 86-91, 2008.

[35] A. C. Alba-Rubio, J. Santamaría-González, J. M. Mérida-Robles et al., "Heterogeneous transesterification processes by using $\mathrm{CaO}$ supported on zinc oxide as basic catalysts," Catalysis Today, vol. 149, pp. 281-287, 2010.

[36] C. Samart, P. Sreetongkittikul, and C. Sookman, "Heterogeneous catalysis of transesterification of soybean oil using KI/mesoporous silica," Fuel Processing Technology, vol. 90, no. 7-8, pp. 922-925, 2009.

[37] J. C. Juan, J. Zhang, and M. A. Yarmo, "12-Tungstophosphoric acid supported on MCM-41 for esterification of fatty acid under solvent-free condition," Journal of Molecular Catalysis A, vol. 267, no. 1-2, pp. 265-271, 2007.

[38] J. Backingham and F. Macdonald, Dictionary of Organic Compounds, Chapman and Hall, London, UK, 1996.

[39] C.-H. Lee and Y.-W. Chen, "Effect of basic additives on $\mathrm{Pt} / \mathrm{Al}_{2} \mathrm{O}_{3}$ for $\mathrm{CO}$ and propylene oxidation under oxygen-deficient conditions," Industrial and Engineering Chemistry Research, vol. 36, no. 5, pp. 1498-1506, 1997.

[40] S. Therdthianwong, C. Siangchin, and A. Therdthianwong, "Improvement of coke resistance of $\mathrm{Ni} / \mathrm{Al}_{2} \mathrm{O}_{3}$ catalyst in $\mathrm{CH}_{4}$ / $\mathrm{CO}_{2}$ reforming by $\mathrm{ZrO}_{2}$ addition," Fuel Processing Technology, vol. 89, no. 2, pp. 160-168, 2008.

[41] H. Hayakawa, H. Tanaka, and K. Fujimoto, "Studies on precipitated iron catalysts for Fischer-Tropsch synthesis," Applied Catalysis A, vol. 310, no. 1-2, pp. 24-30, 2006.

[42] W. Yu, B. Wu, J. Xu, Z. Tao, H. Xiang, and Y. Li, "Effect of Pt impregnation on a precipitated iron-based fischer-tropsch synthesis catalyst," Catalysis Letters, vol. 125, no. 1-2, pp. 116-122, 2008.

[43] D. Predoi, O. Crisan, A. Jitianu et al., "Iron oxide in a silica matrix prepared by the sol-gel method," Thin Solid Films, vol. 515, no. 16, pp. 6319-6323, 2007.

[44] S. Bruni, F. Cariati, M. Casu et al., "IR and NMR study of nanoparticle-support interactions in a $\mathrm{Fe}_{2} \mathrm{O}_{3}-\mathrm{SiO}_{2}$ nanocomposite prepared by a sol-gel method," Nanostructured Materials, vol. 11, no. 5, pp. 573-586, 1999.

[45] S. Bordiga, R. Buzzoni, F. Geobaldo et al., "Structure and reactivity of framework and extraframework iron in Fe-silicalite as investigated by spectroscopic and physicochemical methods," Journal of Catalysis, vol. 158, no. 2, pp. 486-501, 1996.

[46] P. Fabrizioli, T. Bürgi, M. Burgener, S. Van Doorslaer, and A. Baiker, "Synthesis, structural and chemical properties of iron oxide-silica aerogels," Journal of Materials Chemistry, vol. 12, no. 3, pp. 619-630, 2002.

[47] M. Qing, Y. Yang, B. Wu et al., "Modification of $\mathrm{Fe}-\mathrm{SiO}_{2}$ interaction with zirconia for iron-based Fischer-Tropsch catalysts," Journal of Catalysis, vol. 279, no. 1, pp. 111-122, 2011.

[48] S. Velusamy and T. Punniyamurthy, "Novel vanadium-catalyzed oxidation of alcohols to aldehydes and ketones under atmospheric oxygen," Organic Letters, vol. 6, no. 2, pp. 217-219, 2004. 

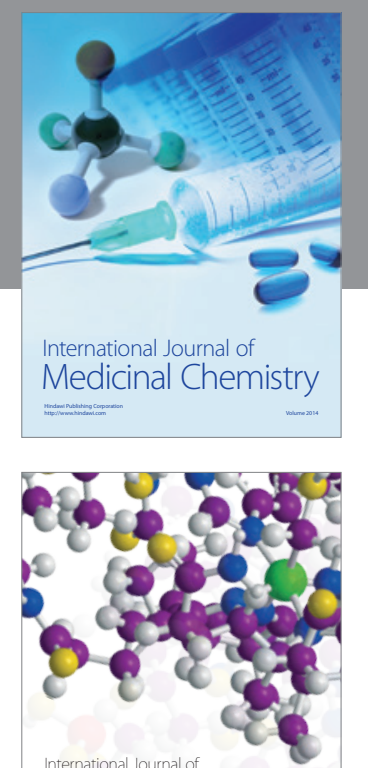

\section{Carbohydrate} Chemistry

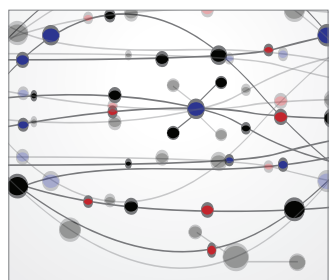

The Scientific World Journal
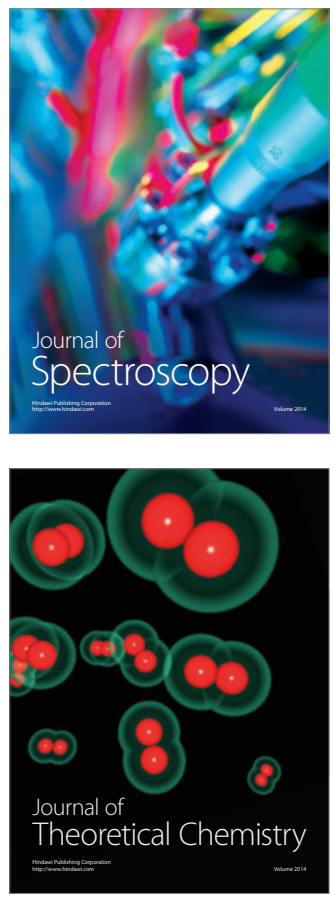
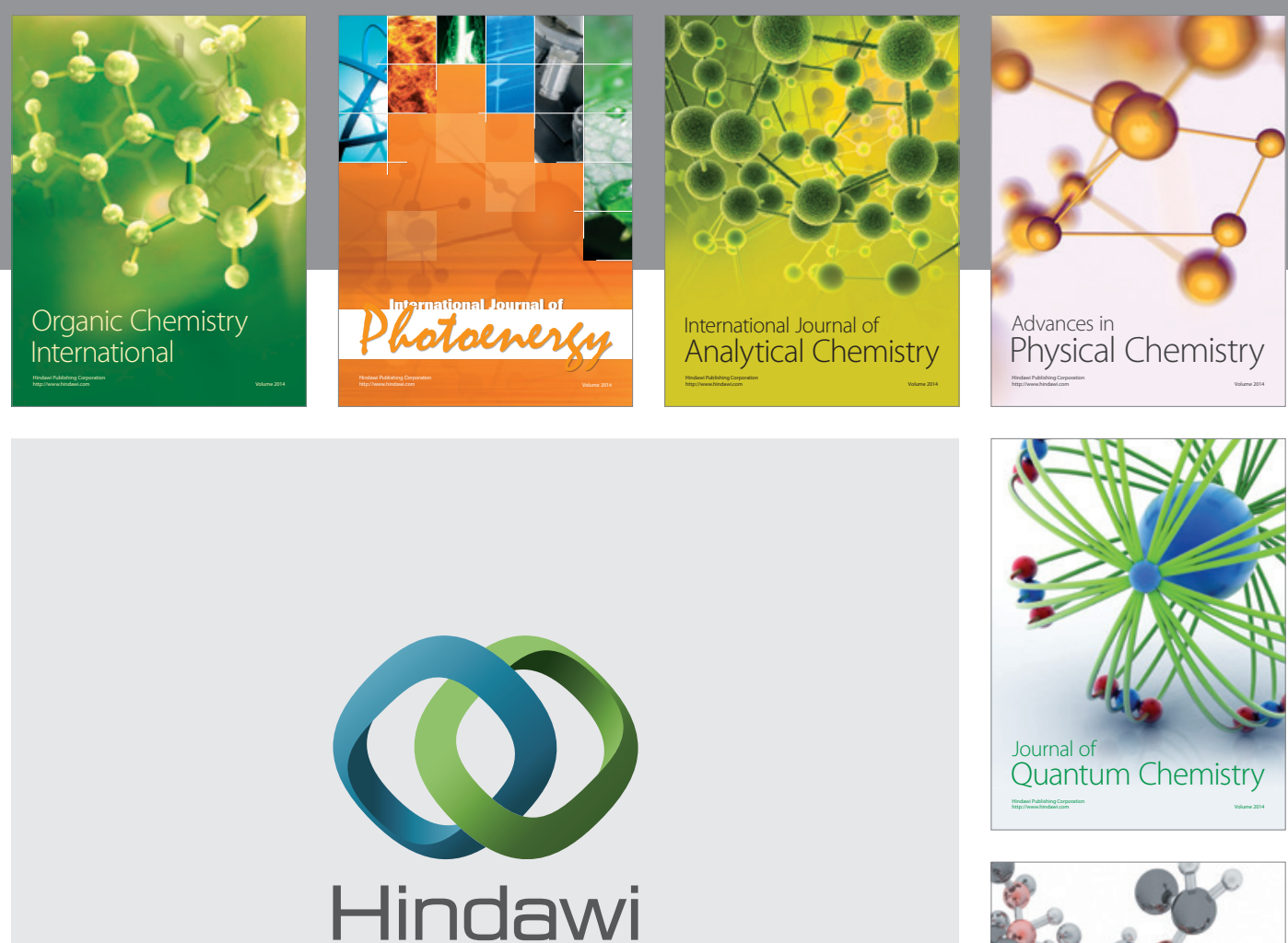

Submit your manuscripts at

http://www.hindawi.com

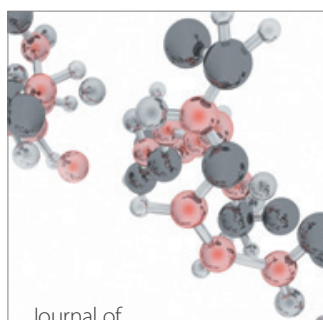

Analytical Methods

in Chemistry

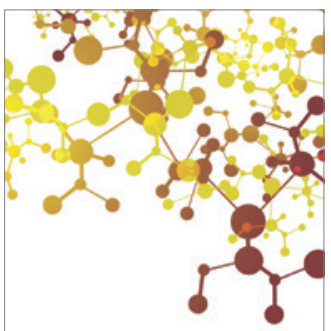

Journal of

Applied Chemistry

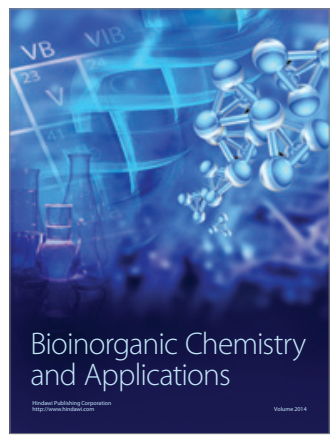

Inorganic Chemistry
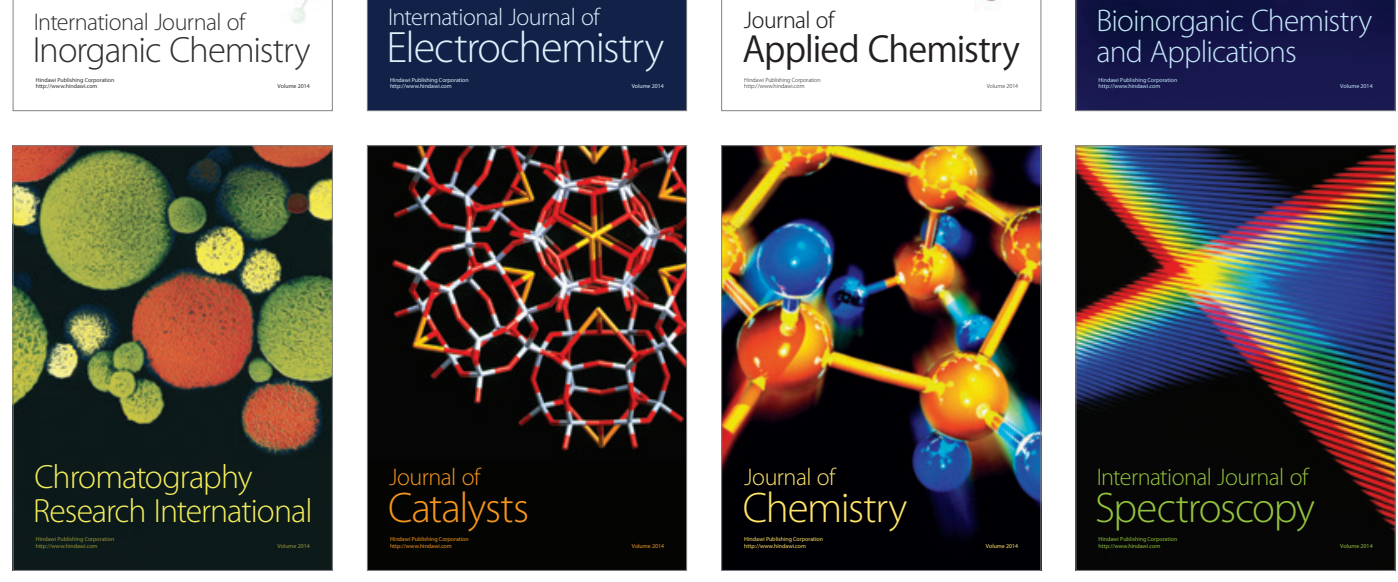